\title{
Phygitally Yours: Examination of Virtual Reality Experiences in Digital Sports and Recreational Games
}

\author{
Arif Yüce ${ }^{1}$, Volkan Aydoğdu², Sevda Gökce Yüce ${ }^{3}$, Hakan Katırcı ${ }^{4}$ \\ ${ }^{1}$ ORCID iD: 0000-0003-3756-3870, Eskişehir Technical University, Eskişehir Teknik \\ Üniversitesi 2 Eylül Kampüsü, 26555 Tepebaşı/Eskişehir, Turkey \\ ${ }^{2}$ ORCID iD: 0000-0001-6044-2618, Eskişehir Technical University, Eskişehir Teknik \\ Üniversitesi 2 Eylül Kampüsü, 26555 Tepebaşı/Eskişehir, Turkey \\ ${ }^{3}$ ORCID iD: 0000-0002-2279-2139, Eskișehir Technical University, Eskișehir Teknik \\ Üniversitesi 2 Eylül Kampüsü, 26555 Tepebaş1/Eskişehir, Turkey \\ ${ }^{4}$ ORCID iD: 0000-0002-2337-7711, Eskişehir Technical University, Eskişehir Teknik \\ Üniversitesi 2 Eylül Kampüsü, 26555 Tepebaş1/Eskişehir, Turkey \\ *Corresponding author, e-mail: arifyuce@eskisehir.edu.tr
}

\begin{abstract}
The demand for, and investment in digital virtual reality (VR) games, both by companies and consumers, are increasing day by day. Accordingly, understanding the experiences created by VR within the scope of phygital marketing is important in terms of contributing to virtual experiential marketing, marketing communication, recreation and similar fields. The concept of phygital, expresses the integral wholeness of the digital and physical. And 'Phygitally Yours' refers to individuals who can live in their own phygital worlds in today's technologies. The aim of this study was to examine the experiences created by digital games involving sports and recreational content within the scope of phygital marketing. Eight individuals who did not have any prior VR experience played digital games with sports (Grand Turismo Sport) and recreational (VR Worlds) content using VR glasses. Subsequently, in-depth interviews were conducted. The data were analysed using the content analysis method, and thematic codes and concepts were revealed and interpreted. As a result of the research, it was determined that the participants' first VR experience of digital games involved the dimensions of sense, interaction, pleasure and flow, with the following codes emerging: perfect holistic effect, showroom feeling, understandable, competition, magic, gorgeous, dilemma, and place independent behaviour.
\end{abstract}

Keywords: Phygital, Virtual Reality Games, Digital Games, Experiential Marketing.

\section{Introduction}

The concept of marketing, which can be briefly expressed as the profitable meeting of human needs along with activities aimed at facilitating these (Kotler, 2000), is constantly affected by the changes created by today's world (Yüce et al., 2017). Although the understanding of marketing has varied over time, some aspects, such as consumption and the consumer, remain constant but also change as a result of innovations brought about by technology within a dynamic process (Kotler et al., 2016). Similarly, individuals' desire and habits of consumption have also been affected by technological changes (Hoffman et al., 2013; Milner, 2016). All these changes and developments have enabled the diversification of products and the development of new marketing approaches (Kotler et al., 2016). As a result, digital marketing is one of the most important marketing concepts that have come to the fore during the digital era.

Digitization has provided the basis for the digitalization of almost all of the daily actions of individuals, and has consequently enabled people to lead more productive lives. In this context, the digital-virtual environment has taken the place of the realphysical environment and has become a guide to the daily habits of individuals

Article History: Received July 18, 2020; Revised January 10, 2021; Accepted April 02, 2021; Published September 02, 2021 
(Odabaşi, 2017). The digital world that emerged as a result of post-digitalization developments since the mid-1990s has brought about digital and post-digital marketing within a progressive process (Chaffey \& Ellis-Chadwick, 2019; Odabaşi, 2017). Digital marketing, which can provide more and more accurate information about customer preferences to manufacturers (Schulz, P., Shehu \& Clement, 2019), can be expressed as the marketing method carried out through digital channels and which brings all marketing applications into the digital environment (Kannan \& Li, 2017). The most important characteristics of digital marketing are its innovative quality and its ability to attract the attention of individuals (Chaffey \& Ellis-Chadwick, 2019). In today's world, digital products offered to users have important features in terms of aesthetics, usability and interaction (Hassenzahl \& Tractinsky, 2006; Nylén \& Holmström, 2015; Tractinsky et al., 2006).

The most recent concept that has developed since the digital world emerged in human life is that of the 'phygital' world (Odabaşi, 2017). The word 'phygital' is a combination of the words 'physical' and 'digital'. The concept of phygital, which expresses the integral wholeness of the digital and physical, refers to a marketing method that provides the most accurate and effective way to reach the consumer by combining the physical and digital world (Belghiti et al., 2017; Moravcikova \& Kliestikova, 2017; R., 2015) (Allison, 2017; Kozlowski, 2017; Vivion, 2016). While popular applications such as Google Glasses, Apple Watch, Virtual Reality (VR) and Augmented Reality (AR), which are known by almost everyone, are examples of digital marketing, the pioneer of phygital marketing is Pokémon Go (Vivion, 2016; Allison, 2017; Kozlowski, 2017).

Phygital marketing adopts the principle of combining users' digital worlds with their physical worlds. In this context, VR and AR applications come to the fore. Although VR technologies have existed since the 90s, especially with the mass marketing of consumer-grade VR headsets in 2016, the interest in VR technologies has increased further and VR technologies have become accessible to most (Ho \& Zhang, 2020). In other words, the development of virtual reality technologies has reached the level where individuals can buy these types of equipment for home-use. Although VR and AR applications directly affect almost every field, the demand and investment made by both companies and consumers in terms of digital games, which are considered the starting point, are increasing day by day (Dickson, 2017; Logan, 2017; Murti \& Varshney, 2018; Pierce, 2018; B. Smith, 2017). Today, although virtual reality technologies are generally associated with the entertainment industry, they have significant potential for use in a much wider area. It is seen how these innovative technologies, which can be applied to many areas, particularly from health to education, from aviation to marketing, are transforming into the familiar real world (Earnshaw, 2014). It is used to improve the learning process in education, making it more fun and, most importantly, efficient.

In addition to creating stronger experiences for students through virtual and augmented reality technologies and visualization of materials, it also allows to practice in environments close to real life and real-time with virtual guided tours (Noh et al., 2009). In addition, although VR games continue to develop in the fields of education, health, and communication, the rapid growth trend in the sports industry can be considered significant in terms of the interaction of existing or potentially developing VR games (Zhai et al., 2020). VR games allow consumers to enjoy a new, unique, and flawless entertainment experience with their unique qualities such as futuristic 
environment, allowing to play rhythm-matching games, which did not exist in previous digital games (Ho \& Zhang, 2020). For this reason, VR games are considered as examples of really new products. The experiential satisfaction that VR games create in individuals affects the consumer's purchasing decisions, while positive experiences make purchasing decisions easier compared to the normal processes. (Javornik, 2016; Ponder, 2013). In other words, the experiential values VR games create in the users directly affect the satisfaction values as well.

Smith and Swinyard (1983) found in the satisfaction-attitude-behavior consistency theory, that a direct game experience allows a more positive satisfactionattitude-behavior consistency. This technology used at this point increases the user's ability to interact with the product, creating experiential value as well as consistent behavior (T.-L. Huang \& Liao, 2015; Schwartz, 2011). In this context, both that the quality of VR games affects the experiential value and that it creates different levels of interactions in individuals has caused companies that produce products and services for VR games to adopt different strategies by considering all these elements. (van Berlo et al., 2021). According to Alcaniz et al. (2019), VR can be seen as a technology directed at consummating or facilitating exchanges. And they suggest that VR marketing is particularly effective because of its ability to enrich consumer experiences. Accordingly, today's leading companies aimed to build relationships with the customers in order to affect their satisfaction positively, and in this regard, they used virtual reality technologies by giving importance to customized experience information (Gheisari et al., 2016; Kounavis et al., 2012).

While the plan created by the consumer to purchase a product is defined as the purchase intention, virtual reality technology has a positive and significant effect on the purchasing intention of the user as it provides the opportunity to easily experience and visualize the product (Dontigney, 2016; Gheisari et al., 2016; Kang, 2014; Papagiannidis et al., 2014). Virtual reality games, which offer an advanced level of interaction, positively affect the consumer's perception of value, as well as create behavioral intentions in the consumer depending on these perceptions of value. Schwartz (2011) states that virtual reality games affect both the positive attitude towards the brand and the purchase intention more because they have three-dimensional visualization (Schwartz, 2011). However, it is stated that virtual reality technologies create a hedonic value in the consumer, and buying intentions are also positively affected depending on these hedonic values and the situation (Chen et al., 2015; Chiu et al., 2014). According to George (2004), the more convenient and flawless the experience and interaction created by virtual reality technology is, the more likely the intention to buy increases in parallel, depending on the satisfaction felt by the consumer.

In marketing, the most effective way to create interest, excitement, and a strong memory to buy a brand or product is to promote the product with the help of the latest technologies. In terms of marketing, augmented, virtual, or mixed reality allows a potential customer to see a virtual prototype of the product, attracting their attention to the product (Boyd \& Koles, 2019; Burke, 2018; Lee, J., Han \& Yang, 2011). In virtual reality games, the characteristics of the products are highlighted by offering the environment closest to the real-life experience to the user individual. Real size, graphics, color harmony and adaptation to reality of virtual applications are considered highly significant (J. Kim \& Forsythe, 2007; Y. Li et al., 2016; Schwarz, 2011). That these features have both high benefit and hedonic value influence user individuals' purchasing decisions depending on cognitive responses (J. Kim \& Forsythe, 2010). 
This situation supports the use of VR applications in order to achieve results that contribute to different disciplines through more functional and different research. Accordingly, understanding the experiences created by VR within the scope of phygital marketing is important in terms of contributing to virtual experiential marketing, marketing communication, recreation and commercial recreation, and similar fields. In light of this, the aim of this research was to examine the experiences of digital games with sports and recreational content within the scope of phygital marketing.

\section{Methods}

Judgemental and snowball sampling methods, which are widely used in qualitative research studies, were utilized to determine the participants (Babbie, 2017; Heckathorn, 2011; Tongco, 2007). Within the scope of judicial sampling and in line with the purpose of the study, individuals who had no previous experience of VR were identified, and on the advice of these individuals, other individuals without such experience were contacted. Accordingly, the study was conducted with a total of eight individuals (six men and two women) on a voluntary basis. Sony PlayStation 4 Virtual Reality Headsets (see Figure 1) and compatible games were used to provide participants with a VR experience. The study was carried out in a laboratory environment isolated from external factors. Participants were respectively asked to play VR Worlds-Ocean Descent (see Figure 2) for the recreational experience and VR Worlds-Danger Ball (see Figure 3) and Grand Turismo Sport (see Figure 4) for the sports experience. The duration of each game was limited to an average of 15 minutes.
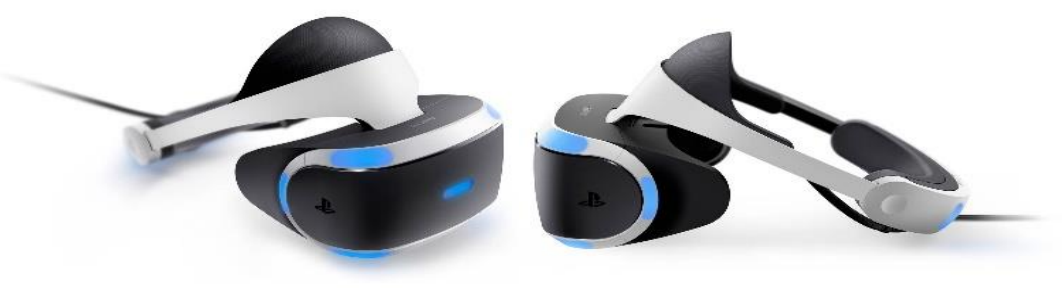

Figure 1. PlayStation 4 Virtual Reality Headsets (source: playstation.com/tr-tr/ps-vr/)

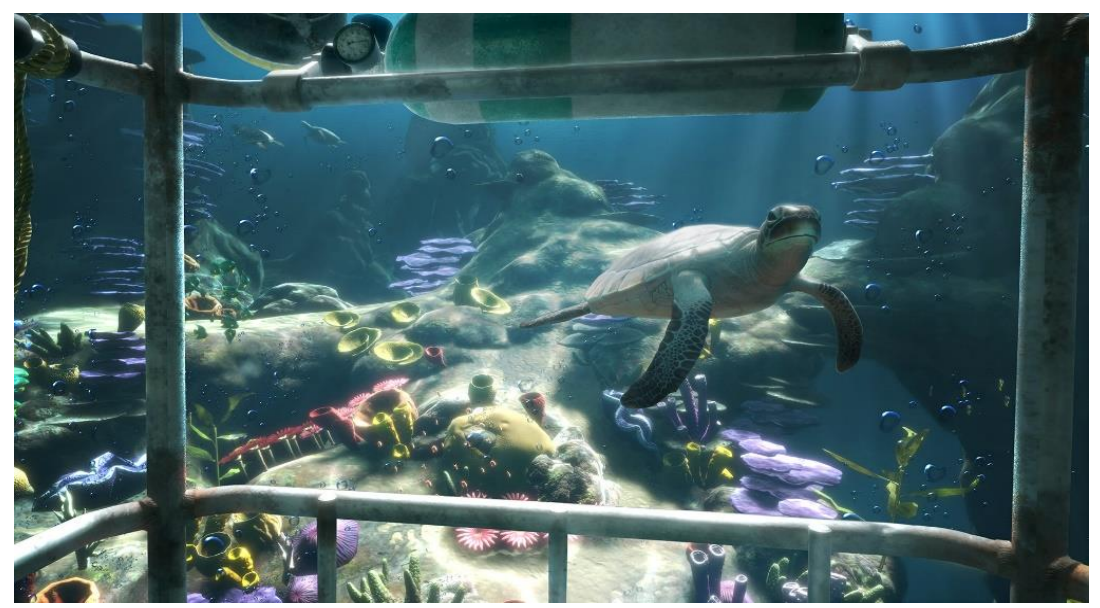

Figure 2. VR Worlds-Ocean Descent (In-Game Images) (source: playstation.com/trtr/games/playstation-vr-worlds/) 


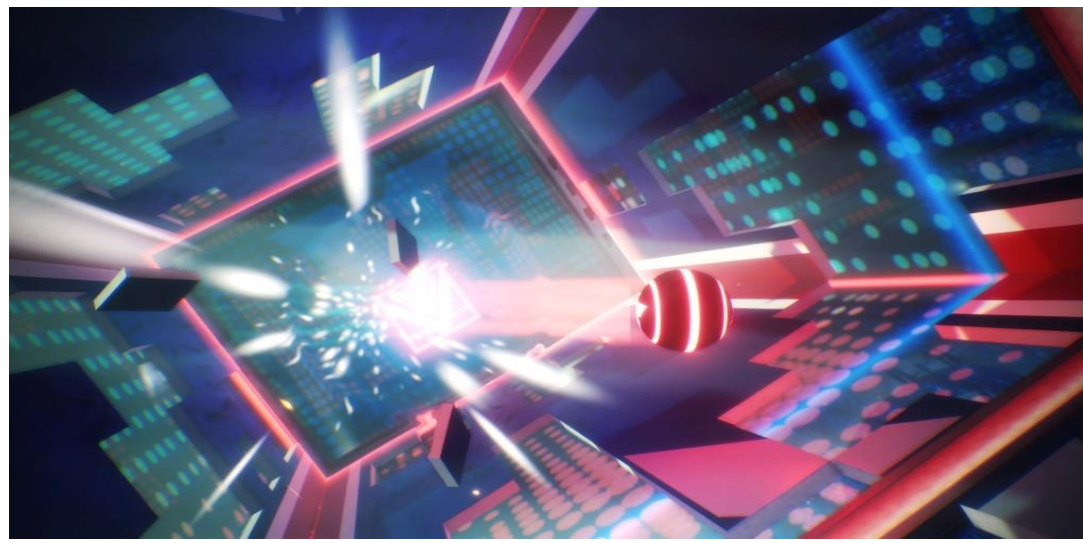

Figure 3. VR Worlds-Danger Ball (In-Game Images) (source: playstation.com/trtr/games/playstation-vr-worlds/)

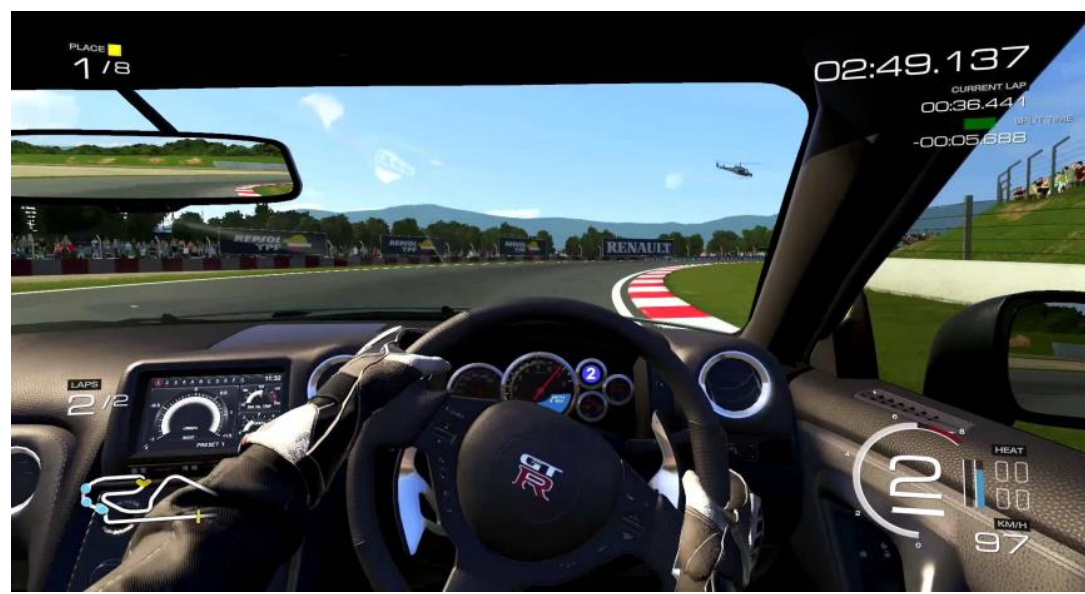

Figure 4. Grand Turismo Sport VR (In-Game Images) (source: granturismo.com/us/gtsport/manual/\#!/arcade/content03)

Following the individuals' experience of the games, in-depth interviews were conducted using a semi-structured questionnaire to determine their VR experiences. The basis and themes of the semi-structured questionnaire, which was designed in the light of the relevant literature and included a total of 10 questions, are the dimensions of virtual experiential marketing put forward by Luo et al. (2011). The relevant dimensions and their contents are briefly explained as follows (Luo et al., 2011): first, sense: sense experiences in virtual environments consist of experiences that appeal to consumers' vision and other senses; second, interaction: this can be expressed as the interaction which occurs in a virtual environment. Situations that constitute interaction consist of experiences such as two-way communication and concurrency; third, pleasure: this can be expressed as an individual's sense of well-being. In other words, this is an individual's experience of feeling happy or satisfied with a situation. The experience of pleasure is a hedonic experience; fourth, flow: flow theory, as originally proposed by Csikszentmihalyi (2007), is considered as experiencing pleasurable situations with positive emotions that motivate consumers in virtual environments and create a mood that leads them to ignore the time spent within the dimension of virtual experiential marketing; and fifth, intention to purchase: this can be expressed as the entirety of the customers' opinion about purchasing a product or service.

In accordance with this framework, questions created by the researchers and related to sense, interaction, pleasure, flow and purchase intention were used when 
preparing the questionnaire. The data obtained from the semi-structured interviews were analysed using content analysis method by four experts with doctoral degrees in their field. The confidence interval of the analysed content was calculated based on the Miles and Huberman (1994) formula. And in this context, a consensus was reached for all codes $(\alpha=1,00)$.

\section{Results}

Demographic information about the participants, and the themes and codes that emerged as a result of the questions posed to them regarding their experiences of digital games with sports and recreational content within the scope of phygital marketing are given below (Table 1., Table 2.):

Table 1. Demographic Characteristics of the Participants

\begin{tabular}{ccccc}
\hline Gender & Age & Education & VR Experience & Code \\
\hline Male & 32 & Postgraduate & No & P1 \\
Male & 31 & Postgraduate & No & P2 \\
Male & 32 & Postgraduate & No & P3 \\
Male & 44 & Postgraduate & No & P4 \\
Male & 28 & Graduate & No & P5 \\
Male & 38 & Graduate & No & P6 \\
Female & 33 & Postgraduate & No & P7 \\
Female & 32 & Graduate & No & P8 \\
\hline
\end{tabular}

Note: Characteristics of the Eight Participants

As shown in Table 1, a total of eight individuals, six men and two women, participated in the study. The ages of these participants with no prior VR experience ranged between 28 and 44 and their educational level was either graduate or post-graduate.

Table 2. Themes and Codes Regarding the Participants' VR Experience

\begin{tabular}{cc}
\hline Theme & Code \\
\hline Sense & Showroom Feeling \\
& Perfect Holistic Effect \\
Magic & Adequate and Simple \\
Interaction & Understandable) \\
Pleasure & Gorgeous \\
& Reality perception \\
& Competition \\
& Dilemma \\
Flow & Time and Place Independent \\
& Behaviour \\
& Purchase Intention \\
\hline
\end{tabular}

Note: Adapted from Luo et al. (2011)

As can be seen in Table 2. and Figure 5., three codes emerged for sense experience, one code emerged for interaction experience, four codes emerged for pleasure experience and two codes emerged for flow experience. 


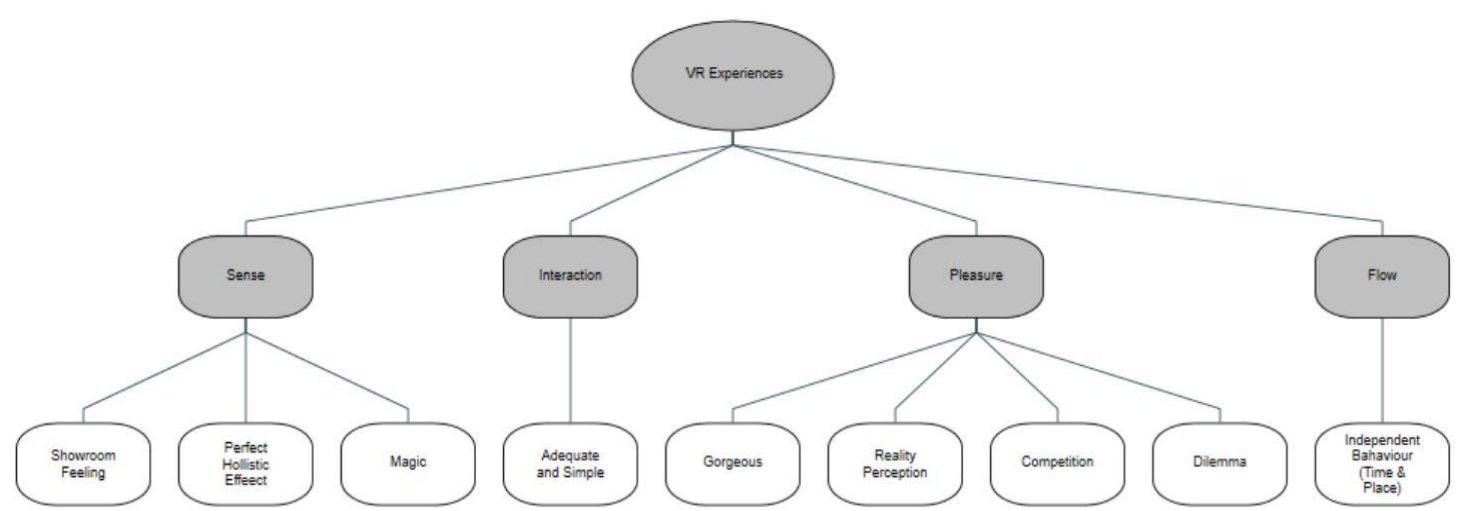

Figure 5. VR Experiences Themes and Codes (source: Luo et al. (2011))

In the interviews conducted in the study, some examples of the themes and codes that emerged were as follows:

1. Sense Theme

The basis of the sense theme created and highlighted within the scope of sensory experiences is the objective of VR equipment and games to create a flawless experience by addressing the senses of participants directly. Accordingly, 'Showroom Feeling', 'Perfect Holistic Effect', and 'Magic' codes were created according to the theme of sense. Explanations and examples of these codes are shown under the relevant sections. Accordingly, participants described the opportunity to review the car closely before the race in the car racing game with the feeling as if they were in the showroom. Another participant stated that he was in a sensually (sound, atmosphere, excetera) perfect holistic effect and he did not realize that he was in virtual reality due to this effect.

\subsection{Showroom Feeling}

Participants, particularly in the racing game, described their experiences both before and during the race with a feeling of being in the showroom. For example, Participant 7 (P7) exemplified this as below: "The ability to take a closer look at the car and examine it before the race created a feeling of being in a showroom" (P7, aged 33, Female).

\subsection{Perfect Holistic Effect}

Some participants exemplified this situation as a perfect holistic effect, stating that they do not feel the difference between the virtual world and the real world as a result of the holistic effect that the sensory effects create in them. Examples of this theme are as follows: "The games offer a sensually flawless holistic effect. People do not realize that they are in VR thanks to the harmony of sound, atmosphere excetera" (Participant 1, aged 32, Male); and Participant 2 (aged 31, Male): "It made me feel that, in general, it almost eliminated the line between VR and real life."

\subsection{Magic}

Participants stated that after wearing the VR head-mounted display, they entered a magical world, and that this technology is almost magical. For example: "After wearing the glasses, I felt as if I had passed through a magic mirror to another world. I got the feeling that I was teleported to another place, like in fairy tales" (Participant 3, aged 32, Male).

2. Interaction Theme

The interaction theme includes features for simultaneous, bi-directional communication elements that affect individuals' experiences in the virtual environment and during VR games. In the research, the code 'adequate and simple' emerged as a 
result of the expressions of help, guidance, and the information to be easily accessible and understandable in VR games played by individuals.

2.1 Adequate and Simple (Understandable)

Participants generally stated that the interaction elements in VR games are sufficient. Related examples are as follows: "I think that the help and instructions are sufficient" (Participant 4, aged 44, Male); and Participant 3 (aged 32, Male): "The instructions were simple, easy to learn and helpful."

3. Pleasure Theme

Pleasure theme contains elements that express hedonic experiences and directly affect purchasing preferences of individuals. 'Gorgeous', 'Reality Perception', 'Competition', 'Dilemma' codes have appeared in the theme of pleasure, which includes codes related to individuals' satisfaction with their experience in VR games. Code contents and examples are as follows:

\subsection{Gorgeous}

Most of the participants expressed their experiences as perfectly magnificent after the VR games they experienced. Examples of expressions of participants in general who express their pleasure experiences in one word within the gorgeous theme are as follows: "Groundbreakingly impressive, exciting" (Participant 3, aged 32, Male); Participant 2 (aged 31, Male): "Fabulous"; and "Unique" (Participant 5, aged 28, Male).

\subsection{Reality Perception}

Some participants stated that each element in VR games creates a complete sense of reality. For example: "I can say that I was excited and felt that I was underwater when the shark was coming towards me" (Participant 4, aged 44, Male).

\subsection{Competition}

Some participants stated that the competitive element in VR games is a pleasure for them adding that they were focusing on competition. For example: "I concentrated on passing vehicles in front of me rather than being in a game” (Participant 5, aged 28, Male).

\subsection{Dilemma}

Participants generally stated that after wearing a VR head-mounted display and playing games for a certain period, they experienced some dilemmas that could cause them to be unable to distinguish between real life and the virtual world. Participants expressed this dilemma created by the perfect qualities of VR games in individuals as follows: "When I first took off the glasses, I still had the feeling of being surprised and having completed a challenging activity. I even had the feeling that I had experienced that short-term high adrenaline feeling at amusement parks" (Participant 6, aged 38, Male); Participant 2 (aged 31, Male): "After playing the game, the processes in the game came into my mind very often. Even though I knew that on the one hand this wasn't real, a part of my brain was saying that it was very realistic on the other. And that made me experience a contradictory situation"; and "So when I came back to the real world, it kept affecting me physically" (Participant 3, aged 32, Male).

4. Flow Theme

Within the scope of the theme created for the flow theory, which has a crucial place within the scope of virtual experiential marketing, the code 'time and place independent behavior' has emerged for the participants addressing to having a time and placeindependent perception of VR games in virtual environments. 


\subsection{Time and Place Independent Behaviour}

While conveying their experiences in VR games, the participants generally stated that they were moved away from time and place and that they tend to continue the game during the process of playing. On the other hand, the exemplary expressions of the participants who stated that the pleasurable experiences were smooth and perfect in terms of realism are as follows: "I could have played the game for hours" (Participant 4, aged 44, Male); Participant 2 (aged 31, Male): "It carried me away in general while playing the game. And the duration was the same as time that goes fast when there are pleasant things happening in real life"; and "If I hadn't taken off the headset, I would have kept on playing ... If it wasn't for my nausea, I think I could have been walking around with VR glasses all day. For a first time, it certainly draws you into things and gives you the feeling that you are playing all the time" (Participant 1, aged 32, Male).

\subsection{Purchase Intention}

The purchase intention theme is the one covering the determination of the participants' intention to purchase VR games or VR-based products according to their experiences after the first VR games. Accordingly, all of the participants responded positively to the following questions directed to them: "Would you like to have a similar experience in the future again?", "Would you spend money on this experience?" and "Would you recommend such an experience to people around you?"

\section{Discussion}

The age of digital transformation that we are in has been called the "Age of Convergenc' (K. Li, 2018). The age of convergence allows for the shaping of electronic and digital media in an integrated structure (Fattal, 2019; K. Li, 2018). This integrated structure has been evaluated by different sectors and in different disciplines and has assumed arole in daily life. It can also be stated that this situation is reflected by consumer choice, as many electronic and digital media based applications are now interconnected (Baird \& Raghu, 2017; Helm et al., 2018). In addition, one of the most important outcomes of the age of convergence is the phygital world, which brings the digital-virtual environment into real physical surrounding.

The most important applications that the phygital world offers to users are VR, AR and mixed reality (MR) applications. Digital games, which are the starting points for these applications, are considered as one of the most important elements in phygital marketing. According to the eMarketer March (2019) user report, approximately 43 million people in the United States use VR applications at least once a month. In addition, according to the Statista (2021) video games report, the VR game market, which was $\$ 9.6$ billion in 2018 , is expected to have a market share of $\$ 22.9$ billion by 2020.These data reveal the economic dimension of digital gaming and VR applications.

As a result of thisstudy, the VR experiences that individuals experienced under the theme of 'sense' are gathered under the codes of 'showroom feeling', 'perfect holistic effect' and 'magic.' Some of the participants likened the opportunity to examine the car closely before the race in the car racing game to the feeling of being in a showroom. And some participants stated that they experienced a sensually perfect holistic effect (sound, atmosphere, excetera) and that they did not realize that they were in VR thanks to this effect. Similarly, one of the participants interpreted his/her sense experience as the disappearance of the line between VR and real life. In their study examining the impact of 2D, 3D and VR applications on digital games, Roettl and Terlutter (2018) concluded that the VR platform gives individuals a better 'sense of 
being there' than other platforms. Shelstad et al. (2017) found that VR applications provided users with more satisfying experiences than other applications. It can thus be stated that the data obtained within the scope of this research have similar characteristics with those in other studies in the international literature. In their study, Hudson et al. (2019) stated that the experience of 'being there' creates satisfaction and that this had positive effects on consumers' purchasing behaviours through word-of-mouth communication. In this context, it can be suggested that experiencing VR through digital games will positively affect the purchasing behaviour of individuals who have not had any prior experience of VR.

The participants' experiences of VR were examined in the context of the dimension of 'interaction', under the code 'adequate and simple (understandable)'. The individuals stated that the help/instructions in the game were sufficient and that they could easily access the information they needed. Dombrowski et al. (2019) found that the design of VR applications, controllability, simplicity and intelligibility in the game menus, and easy accessibility influence individuals' VR experiences. In this context, it can be stated that factors such as simplicity, intelligibility and easy accessibility in digital games that provide a VR experience have a positive effect on the users in terms of their continued use of these applications and their individual satisfaction.

Within the scope of 'pleasure', which is one of the most important dimensions of virtual experiential marketing, the experiences of the participants were examined under the codes of 'gorgeous', 'reality perception', 'competition' and 'dilemma.' According to these codes, the participants described their experiences of pleasure as impressive, and unique enough to break new ground. In addition, the perception of a high-level reality and the element of in-game competition were identified as other factors that affected the experience of pleasure. Christensen et al. (2018) found that in VR applications, players' experiences are directly affected by competition and the extent of immersion. Another element that emerges within the scope of pleasure is the feeling of 'dilemma'. The participants stated that they experienced a tension between real life and VR immediately following their game experience and that this situation created a contradiction between their real world and the virtual world. VR can create an illusion through perfect sound and visual qualities which appeal to the users' senses, and this can lead to different perceptions in individuals (O'brolcháin et al., 2016). The virtual world affects individuals' behaviours in the real world and even creates some changes in these behaviours. This phenomenon, also known as the 'Proteus Effect', is reported to occur intensely with digital games and similar platforms (Jia \& Chen, 2017; Yee et al., 2009). The sense of experiencing a dilemma, which mostly has negative (ethical, health, excetera) effects, was conveyed by the participants as a positive experience with reference to the intense perception of reality perception. Similar results have also been observed in studies carried out on related topics (Christensen et al., 2018; Hudson et al., 2019; Roettl \& Terlutter, 2018). In VR games, which can also be considered hedonic activities, pleasure is one of the important factors in the psychological well-being of individuals (Bronner et al., 2016; Wooden, 2018). On this basis, the satisfaction and pleasure of the consumers in VR games, which can also be thought of as forms of hedonic consumption, may have a positive effect on their intention to purchase (Abbasi et al., 2019, 2017, 2015).

Within the scope of 'flow', individuals stated that they experienced as sense of being independent from time and place, using expressions like 'I could play for hours' and '[It] carried me away.' It is possible to explain the flow experience using 
Csikszentmihalyi's flow theory (2007). The flow experience can be expressed as a period in which all experiences satisfy the individual, and in which certain specific activities with an individual level of optimal difficulty are acquired (Csikszentmihalyi, 2007). When the ways in which individuals express their flow experiences are examined, elements such as 'loss of control' and the 'feeling the sands of time (running faster than normal)' come to the forefront (Nakamura \&Csikszentmihalyi, 2009). Digital games are described as the most successful and interesting applications of the flow experience (Kiili, 2005). Huang et al. (2018) noted that competition and challenge are positively linked to the flow experience and that the need for success strengthens this bond. In addition, it has been stated that individuals who have the flow experience as a result of games and similar cognitive processes experience positive emotions and this creates a commitment to repeat the experience (Yoo et al., 2000). At this point, the results obtained within the research were found to be similar to some international studies. As a result of their experience, all participants stated that they had positive opinions about purchasing VR applications and games in the future. Similarly, Jeng et al., (2017) found that satisfaction from VR and AR experiences directly affected individuals' purchasing behaviour. (Csikszentmihalyi, 2007) cited some of the activities that regularly create flow as sports, games and hobbies. In this context, it can be said that VR applications, which are one of the most important innovations in the digital world, bring together elements of sports, games and hobbies and maximize the feeling of pleasure and satisfaction in individuals.

All participants stated that they would like to have similar experiences in the future and may spend money on these. Suh and Lee (2005) found that VR applications create a positive impression in general and that the features of the applications (information, ease of use, etc.) have significant positive effects on consumers' purchasing decisions. The present study leads to the conclusion that the positive experiences obtained from the games within the framework of sense, interaction, pleasure and flow directly affect purchasing behaviours. Kim and Lee (2000) emphasized that individual values, preferences and motivations have a significant potential for changing consumer behaviours. It can be concluded that positive experiences from VR games will affect the values and motivation of consumers and hence their purchasing preferences. Jeng et al. (2017) found a high, positive correlation between the quality of experience obtained from VR applications within the scope of recreational activities and purchase intention. The positive responses of individuals regarding purchase intention within the scope of the research can be evaluated within this framework. Finally, all of the participants stated that they would like to have similar experiences in the future and that they may spend money on these.

There may be some possible limitations in this study. A total of 8 individuals with no virtual reality experience participated in the research. Although the research sample contains important information to make extensive and important inferences in this type of research, the sample size of the study can be increased to obtain more generalizable and higher representing results. Although that none of the participants had previous virtual reality experience contributed positively to the content of the study, some difficulties were encountered such as organizing the cables, providing the necessary environment, providing detailed information to the users at the stage of practicing the first experiences of individuals in the laboratory and obtaining accurate data. As a result, some participants tried to remove their headphones and VR head-mounted display during the game. There have been some risks associated with the possibility that this 
condition may affect the sensory experience of individuals. In addition, as a result of the excitement and interaction created by the games, some individuals attempted to remove the VR head-mounted display earlier than expected and only shared their experiences until then. All these can be considered as some weaknesses of research. However, the research contains important information about the effect of VR games with sports and recreation content on individuals who have no previous experience. Accordingly, in future studies, the game varieties can be increased, and different experiences can be focused on. In the present study, the importance of flow experience in VR games with sports and recreation content came to the fore. Accordingly, in future studies, some research can be done containing only flow experience and VR games, models can be created, and comparisons can be made about the role of the flow experience as a tool.

\section{Conclusion}

As a result of the research, it has been determined that virtual reality games bring together the elements of sports, games and hobbies, and increase the sense of pleasure and satisfaction in individuals. It is concluded that factors such as simplicity, that is understandability, and easy accessibility have positive effects on users in virtual reality games with sports and recreation content, and this positive effect directly affects the continuous use of applications and individual satisfaction. It has been determined that the cognitive processes involved in virtual reality games enable the streaming experience to be experienced at a high level, and the positive emotions experienced by individuals create a commitment to repeat these experiences. In parallel with this situation, it has been determined that the satisfaction and pleasure of individuals with virtual reality games will positively affect their own purchasing intentions and behaviours as well as the purchasing behaviours of people around them through 'word of mouth' communication. Therewithal, it was concluded that individuals want to reexperience virtual reality games also in the future and are willing to spend money on it. In conclusion, following the first experience of sports and recreation VR applications by consumers with no prior VR experience, it was found that sense, interaction, pleasure and flow consist of completely positive elements, and that all these experiences affect individuals' future purchase intentions in the same direction.

\section{Conflict of Interest}

There is no conflict of interest with any financial, personal, or other relationships with other people or organization related to the material discussed in the manuscript.

\section{Acknowledgements}

The authors would like to thank all participants in this study for their valuable time and sincere interest to the study.

\section{References}

Abbasi, A. Z., Ting, D. H., Hlavacs, H., Costa, L. V., \& Veloso, A. I. (2019). An empirical validation of consumer video game engagement: A playfulconsumption experience approach. Entertainment Computing, 29(SI), 43-55. https://doi.org/https://doi.org/10.1016/j.entcom.2018.12.002.

Abbasi, A. Z., Ting, D. H., \& Hlavacs, H. (2017). Playful-consumption experience in digital game playing: a scale development. International Conference on Entertainment Computing, 290-296. https://doi.org/10.1007/978-3-319-66715- 


\section{2}

Abbasi, A. Z., Ting, D. H., \& Jamek, A. B. S. A. (2015). An integrated conceptual model for predicting behavioral learning triggered by video-game engagement: A mediating role of observational learning. 2015 Game Physics and Mechanics International Conference (GAMEPEC), 11-15. https://doi.org/10.1109/GAMEPEC.2015.7331848

Alcañiz, M., Bigné, E., \& Guixeres, J. (2019). Virtual reality in marketing: a framework, review, and research agenda. Frontiers in Psychology, 10, 1530. https://doi.org/https://doi.org/10.3389/fpsyg.2019.01530

Allison, A. (2017). 'Phygital' is making online-offline experiences seamless. Campaignme.Com. https://campaignme.com/12236/

Babbie, E. R. (2017). The basics of social research (7th ed.). Cengage Learning.

Baird, A., \& Raghu, T. S. (2017). Associating consumer perceived value with business models for digital services. European Journal of Information Systems, 24(1), 422. https://doi.org/https://doi.org/10.1057/ejis.2013.12

Belghiti, S., Ochs, A., Lemoine, J. F., \& Badot, O. (2017). The Phygital Shopping Experience: An Attempt at Conceptualization and Empirical Investigation. Academy of Marketing Science World Marketing Congress, 6174https://doi.org/10.1007/978-3-319-68750-6_18. https://doi.org/https://doi.org/10.1007/978-3-319-68750-6_18

Boyd, D. E., \& Koles, B. (2019). Virtual reality and its impact on B2B marketing: A value-in-use perspective. Journal of Business Research, 100, 590-598. https://doi.org/https://doi.org/10.1016/j.jbusres.2018.06.007

Bronner, S., Pinsker, R., Naik, R., \& Noah, J. A. (2016). Physiological and psychophysiological responses to an exer-game training protocol. Journal of Science and Medicine in Sport, 19(3), 267-271. https://doi.org/https://doi.org/10.1016/j.jsams.2015.03.003

Burke, R. R. (2018). Virtual reality for marketing research. Innovative Research Methodologies in Management, II, 63-82. https://doi.org/10.1007/978-3-31964400-4_3.

Chaffey, D., \& Ellis-Chadwick, F. (2019). Digital marketing (7th ed.). Pearson.

Chen, Y. C., Shang, R. A., Shu, C. Y., \& Lin, C. K. (2015). The Effects of Risk and Hedonic Value on the Intention to Purchase on Group Buying Website: The Role of Trust, Price and Conformity Intention. Universal Journal of Management, 24(1), 85-114. https://doi.org/https://doi.org/10.1111/j.1365-2575.2012.00407.x

Chiu, C. M., Wang, E. T., Fang, Y. H., \& Huang, H. Y. (2014). Understanding customers' repeat purchase intention in $\mathrm{B} 2 \mathrm{C}$ e - commerce: the roles of utilitarian value, hedonic value and perceived risk. Information Systems Journal, 24(1), 85114. https://doi.org/https://doi.org/10.13189/ujm.2015.030605

Christensen, J. V., Mathiesen, M., Poulsen, J. H., Ustrup, E. E., \& Kraus, M. (2018). Player Experience in a VR and Non-VR Multiplayer Game. Proceedings of the Virtual Reality International Conference-Laval Virtual, 1-4. https://doi.org/https://doi.org/10.1145/3234253.3234297

Clement, J. (2021). Virtual reality (VR) video gaming sales revenue worldwide from 2015 to 2020 (in billion U.S. dollars). Statista. https://www.statista.com/statistics/499714/global-virtual-reality-gaming-salesrevenue/

Csikszentmihalyi, M. (2007). Flow and the psychology of discovery and invention. 
HarperCollins.

Dickson, B. (2017). How Augmented Reality Is Transforming Work. PC Magazine. https://uk.pcmag.com/virtual-reality/91594/how-augmented-reality-istransforming-work

Dombrowski, M., Smith, P. A., Manero, A., \& Sparkman, J. (2019). Designing Inclusive Virtual Reality Experiences. International Conference on Human-Computer Interaction, 33-43. https://doi.org/https://doi.org/10.1007/978-3-030-21607-8_3

Dontigney, E. (2016). Brand Image Influence on Purchasing Intentions. Smallbusiness.Chron.Com. https://smallbusiness.chron.com/brand-imageinfluence-purchasing-intentions-70173.html

Earnshaw, R. A. (2014). Virtual reality systems. Academic press.

Fattal, A. L. (2019). Target intimacy: notes on the convergence of the militarization and marketization of love in Colombia. Current Anthropology, 60(19), 49-61. https://doi.org/https://doi.org/10.1086/699911

George, J. F. (2004). The theory of planned behavior and Internet purchasing. Internet Research: Electronic Networking Applications and Policy, 14(3), 198-212.

Gheisari, M., Foroughi Sabzevar, M., Chen, P., \& Irizzary, J. (2016). Integrating BIM and panorama to create a semi-augmented-reality experience of a construction site. International Journal of Construction Education and Research, 12(4), 303316. https://doi.org/https://doi.org/10.1080/01449290500330331

Hassenzahl, M., \& Tractinsky, N. (2006). User experience-a research agenda. Behaviour \& Information Technology, 25(2), 91-97. https://doi.org/https://doi.org/10.1080/01449290500330331

Heckathorn, D. D. (2011). Comment: Snowball versus respondent-driven sampling. Sociological Methodology, $\quad 41(1), \quad 355-366$. https://doi.org/https://doi.org/10.1111/j.1467-9531.2011.01244.x

Helm, S. V., Ligon, V., Stovall, T., \& Van Riper, S. (2018). Consumer interpretations of digital ownership in the book market. Electronic Markets, 28(2), 177-189. https://doi.org/https://doi.org/10.1007/s12525-018-0293-6

Ho, J. C., \& Zhang, X. (2020). Strategies for marketing really new products to the mass market: A text mining-based case study of virtual reality games. Journal of Open Innovation: Technology, Market, and Complexity, 6(1). https://doi.org/https://doi.org/10.3390/joitmc6010001

Hoffman, D. L., Novak, T. P., \& Stein, R. (2013). The digital consumer. In R. Belk \& R. Llamas (Eds.), The Routledge guide to digital consumption (pp. 28-38). Taylor \& Francis. https://doi.org/https://doi.org/10.1007/s12525-017-0283-0

Huang, H. C., Pham, T. T. L., Wong, M. K., Chiu, H. Y., Yang, Y. H., \& Teng, C. I. (2018). How to create flow experience in exergames? Perspective of flow theory. Telematics and Informatics, 35(5), 1288-1296. https://doi.org/https://doi.org/10.1016/j.tele.2018.03.001

Huang, T.-L., \& Liao, S. (2015). A model of acceptance of augmented-reality interactive technology: the moderating role of cognitive innovativeness. Electronic Commerce Research, 15(2), 269-295. https://doi.org/https://doi.org/10.1007/s10660-014-9163-2

Hudson, S., Matson-Barkat, S., Pallamin, N. ., \& Jégou, G. (2019). With or without you? Interaction and immersion in a virtual reality experience. Journal of Business Research, 100 , 459-468. https://doi.org/https://doi.org/10.1016/j.jbusres.2018.10.062 
Javornik, A. (2016). Augmented reality: Research agenda for studying the impact of its media characteristics on consumer behaviour. Journal of Retailing and Consumer Services, 30 ,

252-261. https://doi.org/https://doi.org/10.1016/j.jretconser.2016.02.004.

Jeng, M. Y., Pai, F. Y. ., \& Yeh, T. M. (2017). The virtual reality leisure activities experience on elderly people. Applied Research in Quality of Life, 12(1), 49-65. https://doi.org/https://doi.org/10.1007/s11482-016-9452-0

Jia, J., \& Chen, W. (2017). The ethical dilemmas of virtual reality application in entertainment. 2017 IEEE International Conference on Computational Science and Engineering (CSE) and IEEE International Conference on Embedded and Ubiquitous Computing (EUC, 696-699. https://doi.org/https://doi.org/10.1109/CSE-EUC.2017.134

Kang, J. M. (2014). Augmented reality and motion capture apparel e-shopping values and usage intention. International Journal of Clothing Science and Technology, 36(6), 486-499. https://doi.org/https://doi.org/10.1108/IJCST-05-2013-0055

Kannan, P. K., \& Li, H. A. (2017). Digital marketing: A framework, review and research agenda. International Journal of Research in Marketing, 34(1), 22-45. https://doi.org/https://doi.org/10.1016/j.ijresmar.2016.11.006

Kiili, K. (2005). Digital game-based learning: Towards an experientiallearning model. The Internet and Higher Education, 8, 13-24. https://doi.org/https://doi.org/10.1016/j.iheduc.2004.12.001

Kim, C., \& Lee, S. (2000). Understanding the Cultural Differences in Tourist Motivation between AngloAmerican and Japanese Tourists. In T. K. S. Chon, Inagaki, \& T. Ohashi (Eds.), Japanese Tourists: SocioEconomic, Marketing, and Psychological Analysis. Haworth Press. https://doi.org/https://doi.org/10.1300/J073v09n01_09

Kim, J., \& Forsythe, S. (2007). Hedonic usage of product virtualization technologies in online apparel shopping. International Journal of Retail \& Distribution Management, 35(6), 502-514. https://doi.org/https://doi.org/10.1108/09590550710750368

Kim, J., \& Forsythe, S. (2010). Factors affecting adoption of product virtualization technology for online consumer electronics shopping. International Journal of Retail \& Distribution Management, 38(3), 190-204. https://doi.org/10.1108/09590551011027122

Kotler, P. (2000). Marketing Management Millenium Edition. Prentice Hall.

Kotler, P., Kartajaya, H., \& Setiawan, I. (2016). Marketing 4.0: Moving from traditional to digital (Hoboken). John Wiley \& Sons.

Kounavis, C. D., Kasimati, A. E., \& Zamani, E. D. (2012). Enhancing the tourism experience through mobile augmented reality: Challenges and prospects. International Journal of Engineering Business Management, 4, 10. https://doi.org/https://doi.org/10.5772/51644

Kozlowski, J. C. (2017). Park Permit for Location-Based "Pokémon Go" Games. Parks \& Recreation, 62(1), 86-98.

Lee, J., Han, S., \& Yang, J. (2011). Construction of a computer-simulated mixed reality environment for virtual factory layout planning. Computers in Industry, 62(1), 8698.

Li, K. (2018). Convergence and de-convergence of Chinese journalistic practice in the digital age. Journalism, 19(9-10), 1380-1396. 
https://doi.org/https://doi.org/10.1177/1464884918769463

Li, Y., Zhang, Z., \& Zhao, Y. (2016). Analysis on influencing factors of consumers' purchasing behavior online for furniture. Proceedings of the 18th Annual International Conference on Electronic Commerce E-Commerce in Smart Connected World - ICEC '16, https://doi.org/https://doi.org/10.1145/2971603.2971606

Logan, K. (2017). Why Virtual Reality Will Transform a Workplace Near You. Communications of the ACM, 60, 15-17. https://doi.org/https://doi.org/10.1145/3105444

Luo, M. M., Chen, J. S., Ching, R. K., \& Liu, C. C. (2011). An examination of the effects of virtual experiential marketing on online customer intentions and loyalty. The Service Industries Journal, 31(13), 2163-2191. https://doi.org/https://doi.org/10.1080/02642069.2010.503885

Miles, M, B., \& Huberman, A. M. (1994). Qualitative data analysis: An expanded Sourcebook (2nd ed.). Sage.

Milner, R. M. (2016). The World Made Meme Public Conversations and Participatory Media. The MIT Press.

Moravcikova, D., \& Kliestikova, J. (2017). Brand Building with Using Phygital Marketing Communication. Journal of Economics. Business and Management, 5(3), 148-153. https://doi.org/10.18178/joebm.2017.5.3.503

Murti, S., \& Varshney, A. (2018). How Augmented Reality Will Make Surgery Safer. Harvard Business Review Digital Articles, 4, 2-5.

Noh, Z., Sunar, M. S., \& Pan, Z. (2009). A Review on Augmented Reality for Virtual Heritage System. Learning by Playing. Learning by Playing. Game-Based Education System Design and Development Lecture Notes in Computer Science, 50-61. https://doi.org/https://doi.org/10.1007/978-3-642-03364-3_7

Nylén, D., \& Holmström, J. (2015). Digital innovation strategy: A framework for diagnosing and improving digital product and service innovation. Business Horizons, 58(1), 57-67. https://doi.org/https://doi.org/10.1016/j.bushor.2014.09.001

O’brolcháin, F., Jacquemard, T., Monaghan, D., O'connor, N., Novitzky, P., \& Gordijn, B. (2016). The convergence of virtual reality and social networks: threats to privacy and autonomy. Science and Engineering Ethics, 22(1), 1-29. https://doi.org/https://doi.org/10.1007/s10676-019-09507-0

Odabaşi, Y. (2017). Pazarlama Fijital Dünyanın Neresinde? Brandmap. https://www.brandmap.com.tr/product-page/brandmap-say1-11

Papagiannidis, S., See-To, E., \& Bourlakis, M. (2014). Virtual test-driving: The impact of simulated products on purchase intention. Journal of Retailing and Consumer Services, 21(5), 877-887. https://doi.org/https://doi.org/10.1016/j.jretconser.2014.02.010

Petrock, V. (2019). Virtual and Augmented Reality Users 2019. Emarketer. https://www.emarketer.com/content/virtual-and-augmented-reality-users-2019

Pierce, D. (2018). Virtual Reality Check! Long Touted as Promising Ed Tech Tools, Virtual and Augmented Reality Are Finally Making a Real Impact on Teaching and Learning. THE Journal (Technological Horizons In Education), 45(2), 1418.

Ponder, N. (2013). No Title. http://www.ffi.msstate.edu/pdf/consumer_attitudes.pdf R., M. T. (2015). Getting Phygital, Embracing the space where digital and physical 
intertwine. School Library Journal, 6.

Roettl, J., \& Terlutter, R. (2018). The same video game in 2D, 3D or virtual realityHow does technology impact game evaluation and brand placements. Plos One, 13(7). https://doi.org/https://doi.org/10.1371/journal.pone.0200724

Schulz, P., Shehu, E., \& Clement, M. (2019). When consumers can return digital products: Influence of firm-and consumer-induced communication on the returns and profitability of news articles. International Journal of Research in Marketing, 36(3), 454-470. https://doi.org/https://doi.org/10.1016/j.ijresmar.2019.01.003

Schwartz, A. M. (2011). Augmenting Purchase Intent: An Empirical Study on the Effects of Utilizing Augmented Reality in Online Shopping [University of California, Riverside]. https://papers.ssrn.com/sol3/papers.cfm?abstract_id=1858976.

Schwarz, S. (2011). Affiliate Marketing: A case study of Ticket Express.

Shelstad, W. J., Smith, D. C., \& Chaparro, B. S. (2017). Gaming on the rift: How virtual reality affects game user satisfaction. Proceedings of the Human Factors and Ergonomics Society Annual Meeting, 2072-2076. https://doi.org/https://doi.org/10.1177/1541931213602001

Smith, B. (2017). Living in your design Virtual and augmented reality is enabling engineers. Roadsbridges. https://www.roadsbridges.com/living-your-design

Smith, R., \& Swinyard, W. (1983). Attitude-Behavior Consistency: The Impact of Product Trial Versus Advertising. Journal of Marketing Research, 20(3), 257267. https://doi.org/https://doi.org/10.1177/002224378302000304

Suh, K. S., \& Lee, Y. E. (2005). The effects of virtual reality on consumer learning: an empirical investigation. Mis Quarterly, 29(4), 673-697. https://doi.org/https://doi.org/10.2307/25148705

Tongco, M. D. C. (2007). Purposive sampling as a tool for informant selection. Ethnobotany Research and Applications, 5, 147-158. http://ethnobotanyjournal.org/index.php/era/article/view/126/111

Tractinsky, N., Cokhavi, A., Kirschenbaum, M., \& Sharfi, T. (2006). Evaluating the consistency of immediate aesthetic perceptions of web pages. International Journal of Human-Computer Studies, 64(11), 1071-1083. https://doi.org/https://doi.org/10.1016/j.ijhcs.2006.06.009

van Berlo, Z. M., van Reijmersdal, E. A., Smit, E. G., \& van der Laan, L. N. (2021). Brands in virtual reality games: Affective processes within computer-mediated consumer experiences. Journal of Business Research, 122, 258-265. https://doi.org/https://doi.org/10.1016/j.jbusres.2020.09.006

Vivion, N. (2016). When digital meets physical: What Pokémon Go means for the travel industry,. Sabre. https://www.sabre.com/insights/when-physical-meets-digitalwhat-pokemon-go-means-for-the-travel-industry/

Wooden, S. (2018). Comparative Analysis of The Effects Of Virtual Reality Active Video Game And Controller-Free Active Video Game Play On Physiological Response, Perceived Exertion, And Hedonic Experience [College of Engineering and Computer Science]. https://stars.library.ucf.edu/etd/6164/

Yee, N., Bailenson, J. N., \& Ducheneaut, N. (2009). The Proteus effect: Implications of transformed digital self-representation on online and offline behavior. Communication Research, 36(2), 285-312. https://doi.org/https://doi.org/10.1177/0093650208330254

Yoo, B., Donthu, N., \& Lee, S. (2000). An examination of selected marketing mix elements and brand equity. Journal of the Academy of Marketing Science, 28(2), 
195-211. https://doi.org/10.1177/0092070300282002

Yüce, A., Katirci, H., \& Gökce, S. (2017). From Traditional to Digital Sports Marketing: A Conceptual Study. The Journal of Academic Social Science Studies, 55, 543556. https://doi.org/http://dx.doi.org/10.9761

Zhai, X., Wang, M., Zhou, R., Anwar, M. A., Saneinia, S., Ahmad, I., Li, M., \& Asmi, F. (2020). The Nexus Between VR Affordability, Cognition, and VR Addiction: A Gaming Perspective. 6th International Conference of the Immersive Learning Research Network. 